\title{
Stretching Design Intelligence to Make a Difference
}

\section{Maurizio Sabini}

Designing for social impact has a long history and a recent phase of renewed awareness and interest.

For the former, one could go back to the social concerns of the Modern Movement and its research and experimentations for affordable housing and a "functional city" that had the ambition (soon become an illusion) of making urban opportunities available to all. It was not until the late 1960 s and the 1970s that a new approach started to emerge. From the 1968 keynote address by Whitney M. Young Jr. at the American Institute of Architects convention in New York, to Giancarlo De Carlo's 1970s experiments of "participatory planning and design," culminated with his seminal article "An Architecture of Participation" (Perspecta 17, 1980), to the founding in 1993 of the Rural Studio at Auburn University by Sam Mockbee and Dennis K. Ruth, to the launching in 1999 of Architecture for Humanity, to the 2005 Global Studio, a collaboration led by Anna Rubbo among the University of Sydney, Columbia University, and the University of Rome, to the 2008 The Design for Social Impact workshop and the IDEO-designed toolkit, to the 2010-11 exhibitions at MoMA ("Small Scale, Big Change") and at the UN Headquarters in New York ("Design with the Other 90\%: CITIES," organized by Smithsonian's Cooper-Hewitt, National Design Museum), and the launching in 2011 of IDEO.org "as a nonprofit design organization focused solely on social innovation, enabling IDEO to make an even bigger impact on global poverty." 1

Regarding the more recent phase of renewed awareness and interest, the 2016 Venice Biennale "Reporting from the Front" certainly represented a culminating point. Beyond the inevitable criticism and polemic that every 
Biennale stirs (and that is actually expected and desirable), the exhibitions orchestrated by Alejandro Aravena and his team conveyed an unequivocal general message: our current design and planning culture no longer sees "social impact design" just as an ethical mandate, but as a stimulating, expanded field of operation where its highly complex problems challenge and demand our best design and planning intelligence. As Alejandro Aravena put it, "these difficult complex issues require professional quality, not professional charity... socially minded architecture is a choice, not a responsibility... the more complex the issue, the more the need for synthesis." ${ }^{2}$

With the call for submissions for this first themed issue of the TPJ we wanted precisely to gauge, at this point in time, our design and planning intelligence around these issues. How do we leverage the power of design to actually, as designers, make a difference? What does it mean "designing for social impact" beyond socio-economical analysis and reporting, or before it becomes political activism and advocacy? How do we grow our design intelligence and sharpen our design tools to make our projects more relevant for society? And how do we assess social impact for design interventions? From the many, interesting contributions received, we identified, through a difficult but rigorous selection process, those that could more clearly illustrate innovative research on this topic from a variety of angles: from historical/theoretical critiques on the state of the discussion, to typological or technological investigations, to cross-disciplinary studies, to projects of reflective practice for specific sites and contexts, to evaluation of, and/ or proposals for, new forms of urbanism, to experimental pedagogies. The landscape that emerges out of this highly articulated array of contributions is one of a very dynamic, vibrant and experimental design and planning culture that bodes well for future inquiries, experimentations and accomplishments.

Our intention, with this issue, was to offer an opportunity of reflection on what has already become a fundamental and integral aspect of our practice and research, although too often a-critically dismissed as the "design version of do-goodism" or too superficially embraced as "the real call" for the design fields where professional expertise simply supports an agenda of activism. We hope that this issue will help appreciate how such complex political, economic, cultural, technical and environmental issues and challenges represent real opportunities for our design intelligence, if properly stretched, to make a difference in the world.

\footnotetext{
1 Design and Social Impact, a white paper based on the "Social Impact Design Summit," a convening by the Smithsonian's Cooper-Hewitt, National Design Museum, the National Endowment for the Arts, and The Lemelson Foundation at The Rockefeller Foundation offices in New York on February 27, 2012 (New York: Smithsonian Institution Cooper-Hewitt, National Design Museum, 2013), 18.

2 "Architects have no moral obligation to society says Alejandro Aravena," Dezeen, February 23, 2016. http://www.dezeen.com/2016/02/23/architects-have-no-moral-obligation-to-societysays-alejandro-aravena-venice-architecture-biennale/
} 